\title{
O PIBID E SUAS CONTRIBUIÇÕES NA QUALIFICAÇÃO DO COTIDIANO ESCOLAR
}

\author{
MAGDA MARLY FERNANDES \\ PATRÍCIA CRISTINA SANTOS DA SILVA
}

\begin{abstract}
RESUMO
As políticas públicas para a qualificação da formação docente são ações necessárias para a melhoria da qualidade na educação básica. Nesse contexto, o Programa Institucional de Bolsa de Iniciação à Docência - PIBID $^{1}$ - visa a oferecer, por sua configuração, uma dinâmica na formação básica aos futuros professores, com experiências e saberes em diferentes dimensões essenciais à profissão. Os estudantes vivenciam o trabalho interdisciplinar, com atuação em processos grupais, e são instigados a buscar distintas metodologias para favorecer a aprendizagem, além da prática de registros para a análise crítica dos contextos de ensino. Sendo assim, o programa afronta o currículo e transcorre em paralelo à vida dos universitários e dos escolares. O texto apresenta a percepção de coordenadoras de área frente a atuação do PIBID na formação dos estudantes e sua consolidação no trabalho desenvolvido nas escolas públicas. Foram realizadas observações nas
\end{abstract}

\footnotetext{
O Programa Institucional de Bolsa de Iniciação à Docência - PIBID é um programa de incentivo e valorização do magistério e de aprimoramento do processo de formação de docentes para a educação básica, vinculado à Diretoria de Educação Básica Presencial - DEB - da Coordenação de Aperfeiçoamento de Pessoal de Nível Superior - CAPES. O PIBID oferece bolsas para que alunos de licenciatura exerçam atividades pedagógicas em escolas públicas de educação básica, contribuindo para a integração entre teoria e prática, para a aproximação entre universidades e escolas e para a melhoria de qualidade da educação brasileira. Para assegurar os resultados educacionais, os bolsistas são orientados por coordenadores de área - docentes das licenciaturas - e por supervisores - docentes das escolas públicas onde exercem suas atividades. <http://www.ufvjm.edu.br/prograd/pibid.html>
} 
escolas parceiras públicas de Ensino Fundamental I, diálogos com gestores, docentes e com os/as bolsistas licenciandos/as que nos permitiram discorrer sobre os cuidados fundamentais para que o PIBID seja aceito e aproveitado no currículo da escola. Foi verificado que as escolas observadas valorizam e respeitam o PIBID, reconhecendo o Programa como parte da instituição pública. Os estudantes são acolhidos e convidados a vivenciarem o cotidiano escolar com um olhar reflexivo e formativo. Percebe-se que há um amadurecimento, com mudança de postura dos bolsistas de passivo para uma postura ativa em termos de iniciativa a respeito da prática pedagógica, com produção positiva de resultados que são apresentados inclusive fora do Estado.

Palavras-chave: PIBID. Docência. Currículo.

\begin{abstract}
Public policies for the qualification of teacher training are necessary for the improvement of basic education. In this context, the Institutional Program of Scholarships for the Initiation to Teaching - PIBID [1] aims to give a dynamic basic training for future teachers, offering essential experience and knowledge in different dimensions. The scholarship university students experience interdisciplinary work in group processes, and are motivated to look for and use different methodologies to promote learning. Also, they are encouraged to make records of these practices to allow the critical analysis of the teaching contexts. Nevertheless, the program confronts the regular curriculum and runs in parallel to the university students' and schoolchildren's lives. This text brings the perception of area coordinators regarding the performance of PIBID in teacher training and its consolidation in the work carried out on public schools. Field observations in Elementary Education I classes from public schools, and conversations with managers, teachers and scholarship students allowed us to write about the fundamental steps that need to be taken in order to PIBID to be accepted and approved in the curriculum of the school. It was verified that the observed schools value and respect PIBID, recognizing the Program as part of the public institution. The students are welcomed and invited to experience the daily
\end{abstract}


school life with a reflective and formative look. It was noticed that the scholarship students are maturing and changing their posture from a passive to an active position in terms of taking the initiative about pedagogical practices, with positive results, that were recorded even outside the state.

Key-words: PIBID. Teaching. Curriculum.

\section{INTRODUÇÃO}

A formação inicial de professores sempre foi um tema de discussão necessária em todo o mundo. No Brasil, há muitos estudos e pesquisas que demonstram fragilidades nos cursos de licenciatura.

Em 2010, a autora Bernadete Gatti realizou um estudo pela Fundação Carlos Chagas analisando a formação de professores no Brasil, bem como, as suas características e problemas, revelando a complexidade do tema em questão. A propósito da licenciatura em pedagogia, a pesquisa revela que, atualmente, o curso é responsável pela formação de professores para atuarem nos segmentos do $1^{\circ}$. ao $5^{\circ}$. ano do ensino fundamental I e com a faixa etária que compreende o atendimento a crianças de 0 a 5 anos de idade (educação infantil), articulando ainda as discussões sobre a Educação de Jovens e Adultos, a Educação não Formal, a inclusão e a gestão, áreas de atuação do profissional licenciado em pedagogia.

Disciplinas relativas à "Educação Infantil" representam apenas 5,3\% do conjunto, e as relativas à "Educação Especial", 3,8\%. Nas ementas encontra-se o mesmo cenário ora descrito. Os cursos estão incorporando tais questões em um conjunto de disciplinas que acentuam abordagens mais genéricas ou descritivas das questões educativas, com poucas referências às práticas possíveis e suas lógicas. Alguns poucos cursos fazem o aprofundamento em relação a uma ou outra dessas áreas disciplinares, bem como para Educação de Jovens e Adultos, ou Educação não formal etc., seja mediante a oferta de optativas, seja de tópicos e projetos especiais, mas neles não é possível detectar a 
predominância de elementos voltados para as práticas docentes propriamente ditas, como uma construção integrada a conhecimentos de fundo. O estudo das ementas das disciplinas revela, antes de tudo, maior preocupação com o oferecimento de teorias políticas, sociológicas e psicológicas para a contextualização dos desafios do trabalho nesse nível e nessas modalidades de ensino. Isto é importante para o trabalho consciente do professor, mas não suficiente para suas atividades de ensino (GATTI, 2010, p. 1.371, grifos da autora).

$\mathrm{Na}$ pesquisa, a autora questiona se essa formação "[...] é suficiente para o futuro professor vir a planejar, ministrar e avaliar atividades de ensino para os anos iniciais do ensino fundamental e para a educação infantil. A constatação é de que há uma insuficiência formativa evidente para o desenvolvimento desse trabalho" (IBID., p. 1.372).

Nesse sentido, é oportuno afirmar que se manter integrado às novas metodologias de ensino para uma prática de ensino cada vez mais eficiente é um dos grandes desafios da profissão professor.

Esses fatos fundamentam a compreensão do PIBID como uma política pública que abrange não apenas a formação inicial de professores. Nota-se uma completude formativa do programa, que contribui para a formação em serviço de professores e gestores das escolas públicas e ainda para a formação de professores formadores das IES. Entendemos que a ação política na prática docente nem sempre é fácil e nem sempre agrada a todos, pois se trata de uma potência incrível com forças estratégicas e energia para atacar a pobreza estrutural do conhecimento. Levar estudantes a encontrarem um sentido na carreira docente, refletindo a respeito de sua identidade e função profissional é tarefa necessária. Deve-se insistir na ação docente sem corromper-se da função, desistindo do compromisso ético, contaminados pelo velho pensar "deixe como está". Seguindo esse raciocínio, a orientação que integra os pibidianos tem um viés político de formação pedagógica que visa gerar acesso aos conhecimentos 
e ânimo à superação pessoal, considerando que "não é possível discutirmos sobre a formação de professores sem considerarmos o cotidiano escolar e, consequentemente, a profissionalidade docente" (BAHIA e SOUZA, 2014, p. 341). Essa prerrogativa faz que os futuros docentes, ao se defrontarem com o cotidiano da escola pública junto às crianças, busquem inovações que melhorem o acesso ao conhecimento, qualificando sua formação e consequentemente elevando a qualidade na educação básica.

A reflexão proposta neste trabalho surge, portanto, no diálogo de experiências práticas que revelam o cotidiano do PIBID, mais especificamente no acolhimento que as escolas oferecem aos estudantes e a dinâmica dos trabalhos desenvolvidos. No Programa, os estudantes do curso de pedagogia são recebidos nas escolas parceiras e acompanhados pela professora da IES e pela supervisora que é docente na própria escola no contraturno. Na escola, os/as licenciandos/as conhecem o espaço escolar, bem como, os seus agentes. Conhecem as crianças, seus professores e são convidados a participarem das reuniões de planejamento da escola junto à gestão e os docentes. É nesse espaço formativo que dialogam sobre o projeto político pedagógico, acerca da metodologia de ensino, bem como, a respeito das concepções pedagógicas. Esse espaço de diálogo é importante na construção de conhecimento e de acordo com Bahia e Souza (2014):

Assim, vai se evidenciando a disseminação dos estudos sobre o cotidiano, sobretudo a ampliação destes enquanto investigação da realidade escolar, ou do cotidiano escolar, e emerge uma diversificação de olhares, perspectivas e abordagens em busca do desvelamento e compreensão dos diferentes conhecimentos nos/dos/com os cotidianos. Mas, como as discussões sobre o cotidiano sempre envolveram questão do senso comum, isso significou uma tensão para a área (p. 352).

A partir desse reconhecimento do cotidiano, os/as estudantes iniciam um trabalho investigativo, de pesquisa e ação-reflexão 
junto aos docentes, na busca da compreensão das necessidades do processo de ensino e aprendizagem das crianças no ensino fundamental I. São construídos projetos e desenvolvidos ao longo do período letivo. Há também as reuniões formativas nas IES, que buscam mobilizar discussões de problemáticas que surgem no dia a dia da escola. Nesse espaço formativo, procura-se a participação da tríade, estudante, supervisor e coordenador de área. É possível notar a qualidade da formação em serviço proporcionada pelo PIBID, no pequeno texto a seguir:

Aproveitamos um tema da atualidade para propror atividades contextualizadas que pudesse desenvolver a linguagem oral e escrita dos alunos. Planejamos uma sequência didática que teve início em abril com quatro semanas de duração. Inicialmente foi apresentado um video debate sobre Prevenção da Dengue, Zica e Chikungunya mediado pelas bolsistas, no qual todos os alunos puderam participar dando a sua opinião sobre as informações do vídeo. $\mathrm{Na}$ aula seguinte as bolsistas trabalharam com o gênero textual receita e ensinaram os alunos a fazerem um repelente caseiro. Em continuidade, foi desenvolvida uma atividade de leitura de um cordel da dengue e posteriormente a organização deste após recorte (texto fatiado) formando cartazes. E por fim, as bolsistas realizaram uma oficina de mensageiros do vento, para incentivar a reutilização de materiais e evitar o descarte indevido e provável acúmulo de água (RELATÓRIO DE PROFESSOR SUPERVISOR, 2016).

Nesse pequeno texto extraído de um dos relatórios da supervisora, ficam evidentes o diálogo, o planejamento e a ação-reflexão-ação que são vivenciados no cotidiano escolar pelas licenciandas pibidianas. Nesse sentido, pela importância do trabalho do PIBID, delineamos alguns pontos importantes:

O PIBID "dentro da escola": é necessário compreender que o programa de formação docente não é um projeto solto ou um apêndice na escola, passível de ser extirpado quando há mudança de gestores ou das políticas de governos. Mas como 
programa de mudança na cultura da prática docente, reinventando fazeres na condução dinâmica da aprendizagem e desempenhando um papel importante na configuração da identidade docente. Este é um esclarecimento de entrada na escola, que precisa ser reforçado por todos, um ponto de convencimento e abertura política na escola. O PIBID é acolhido na escola pública e se torna um programa parceiro da educação com qualidade. Nota-se que o PIBID mobiliza práticas e posturas dentro da escola e que o projeto pertence à escola.

O supervisor docente: é possível perceber a importância do supervisor como o coformador na formação inicial dos licenciandos. Esse profissional orienta e acompanha os estudantes em formação e é a ponte entre a escola e a universidade. O supervisor e o coordenador de área realizam a orientação e a supervisão na aplicação do projeto na escola objetivado pelo programa. Sua constante busca deve inferir nas questões vivas do currículo, nos campos que requerem replanejamento em temas não tão explícitos, porém, revelados no cotidiano escolar. O supervisor e o coordenador de área têm o papel de problematizar as situações práticas negativas e positivas mobilizando os saberes dos licenciandos e consequentemente construindo conhecimento.

Foi um ano de grandes aprendizados, parcerias e muito, muito aprendizado, de ambos os lados. É muito gratificante trabalhar com pessoas comprometidas com a educação e certos de que esse realmente é o caminho que querem seguir. Vou levar para o resto da minha vida, a experiência de ter participado de um projeto tão importante e grandioso. Obrigada, PIBID, por esses dois anos de crescimento pessoal e profissional (RELATÓRIO DA SUPERVISORA B, 2015).

É imprescindível compreender as crianças ou jovens que são atendidos na escola. Verificar como compreendem o seu percurso, como estão sendo marcados historicamente, quais práticas são mais eficazes, o que buscam em seus pensares considerando a sociedade onde vivem. O mesmo se dá ao escutar os anseios dos estudantes pibidianos, como analisam os escolares, seus ta- 
bus e preconceitos, como usam um conceito teórico dissociados do pensar vivido na prática, como criam uma comunicabilidade com as crianças, onde está a força de sua conspiração. Daí a importância da escuta ativa também dos pibidianos sobre a gestão do trabalho pedagógico e como reagem aos problemas.

A atuação do coordenador de área na articulação dos saberes oferecidos no curso de pedagogia e a atuação dos estudantes no cotidiano escolar referenciado por essa formação acadêmica. Nota-se que do movimento educativo que envolve a tríade: coordenador de área, aluno licenciando e escola pública, surge a necessidade constante de reflexão sobre o currículo do próprio curso superior, já evidenciado por Gatti (2010):

No que concerne à formação de professores, é necessária uma verdadeira revolução nas estruturas institucionais formativas e nos currículos da formação. As emendas já são muitas. A fragmentação formativa é clara. É preciso integrar essa formação em currículos articulados e voltados a esse objetivo precípuo. A formação de professores não pode ser pensada a partir das ciências e seus diversos campos disciplinares, como adendo destas áreas, mas a partir da função social própria à escolarização - ensinar às novas gerações o conhecimento acumulado e consolidar valores e práticas coerentes com nossa vida civil (p. 1.375).

A criação de ambientes culturais na escola, difusão dos trabalhos das crianças para a comunidade não só em datas festivas, mas de maneira permanente. Trata-se de uma prática que permanece viva e produz um sentimento de pertencimento e diálogo dentro da comunidade escolar. Um ambiente de educação e de cultura para a evolução das pessoas que compartilham o mesmo espaço de conhecimento.

Consideramos que há muita coisa a ser pensada e realizada na universidade. Cada pibidiano, quando vivencia essa dinâmica, procura desenvolver por seus próprios meios trabalhos de realização pessoal alinhado ao profissional, num diálogo de reflexão que lembra Alípio Marcio Dias Casali (professor da PUC-SP), 
quando ele afirma que a crise que vem se desenvolvendo na educação é uma crise de "substância do conceito de ação política e de ética decorrente de uma formulação ideológica que inverteu posições entre povo e poder" (CASALI, 2007:2). ${ }^{2}$ Enfatiza que nessa relação há um sentido preconceituoso de que a classe popular deve obedecer aos governos, e este, mandar no povo, além da falsa ideia de que a população não sabe fazer política. Esse pensamento imposto é o que vem abalando a concepção de currículo e seus campos constitutivos da ação pedagógica, o espaço de poder sobre os alunos, os conteúdos, a maneira como são ensinados, a formação das salas etc.

Os alunos atuaram ativamente das atividades práticas expressando suas experiências e seus conhecimentos sobre o cultivo de plantas. Da mesma forma, eles receberam com muita empolgação as atividades interdisciplinares ligadas à alfabetização e ao letramento. Neste sentido, foram trabalhados gêneros textuais como letra música, poema, texto informativo, conto e narrativas como os contos de tradição oral e histórias de vida. Da mesma forma, os alunos foram motivados a construírem histórias coletivas a partir de técnicas de contação de história. Como resultados, pode-se destacar a aprendizagem de técnicas para o plantio da horta vertical no pallet, assim como a evolução das hipóteses de leitura e escrita dos alunos e a construção de conhecimentos a respeito dos gêneros textuais. Além disso, verificaram-se também reflexões e a conscientização por parte de alunos e de bolsistas sobre a importância do consumo de alimentos saudáveis, assim como a respeito da proteção da natureza. O Projeto Horta presenteou a escola com uma horta vertical feita no pallet, deixando para todos os alunos e professores da Escola o exemplo da importância da relação entre escola, natureza e realidade

\footnotetext{
CASALI, Alípio Marcio Dias. Política, Ética e Educação. Conferência proferida no II Congresso Nacional Juvenil de filosofia y Pedagogia: los jovenes frente a La ética e La política Normal de Bucaramanga nos dias 22, 23, 24 de agosto de 2007. Inédito.
} 
dos educandos no ensino-aprendizagem interdisciplinar e na construção de conhecimentos ligados aos conteúdos conceituais, procedimentais e atitudinais (RELATÓRIO DE ALUNA PIBIDIANA, 2016).

Enrique Dussel (1998. In: CASALI, 2007) leva em conta as leis da natureza humana, a luta pela vida, a vontade de viver e de ser respeitado e atendido em suas necessidades, onde a ética dá um sentido inerente indispensável à ação política. Ele traz para dentro da escola esse sentido da vontade de viver do estudante enquanto ser individual, e coletivo, a necessidade de agregar-se e de se comunicar, compartilhar conhecimentos e experiências, medir desejos, reorganizar pensares ao criar possibilidades. Nessa perspectiva, é possível inferir que o PIBID tem contribuído com a construção dos saberes docentes. Ressaltamos ainda a necessidade de ampliação do programa para que mais estudantes, professores e gestores possam vivenciar a docência de maneira rica e consolidada, desenvolvendo boas práticas na escola pública e contribuindo com a melhoria da educação básica do país.

\section{REFERÊNCIAS}

APPLE, Michael, W. Ideologia e Currículo. Porto Alegre: Artmed, 2006. BAHIA, Norinês Panicacci, e Roger Marchesini de Quadros Souza. "O Curso de Pedagogia e o PIBID: o cotidiano escolar fazendo a diferença/Educational courses and PIBID: school routine making the difference." REVISTA ELETRÔNICA PESQUISEDUCA 6.12 (2015): 339-363.

CASALI, Alípio Marcio Dias. Política, Ética e Educação. Conferência proferida no II Congresso Nacional Juvenil de filosofia y Pedagogia: los jovenes frente a La ética e La política Normal de Bucaramanga nos dias 22, 23, 24 de agosto de 2007. Inédito.

CHAUI, Marilena. Cultura e democracia. In: Crítica y emancipación: Revista latinoamericana de Ciencias Sociales. Año 1, n. 1 (jun. 2008-). Buenos Aires: CLACSO, 2008- . - ISSN 1999-8104, p. 70-75.

Disponível em: < http://bibliotecavirtual.clacso.org.ar/ar/libros/secret/CyE/ cye3S2a.pdf $>$

GATTI, Bernadete Angelina. Formação de professores no Brasil: características e problemas. Educação e Sociedade. Campinas, v. 31, n. 113, p. 1.355-1.379, 2010.

MOREIRA, Antonio Flávio Barbosa. Indagações sobre currículo: currículo, conhecimento e cultura. Brasília: Ministério da Educação Básica, 2007. 
SEVERINO, Antônio Joaquim. A prática tridimensional como mediação do existir. In: Educação, sujeito e história. São Paulo: Olho D’Agua, 2006.

\section{SOBRE AS AUTORAS}

Magda Marly Fernandes é Coordenadora de área Subprojeto Pedagogia UNICSUL.

Patrícia Cristina Santos da Silva é egressa do PPGE/Metodista e Coordenadora de área Subprojeto Pedagogia EAD/Metodista. 